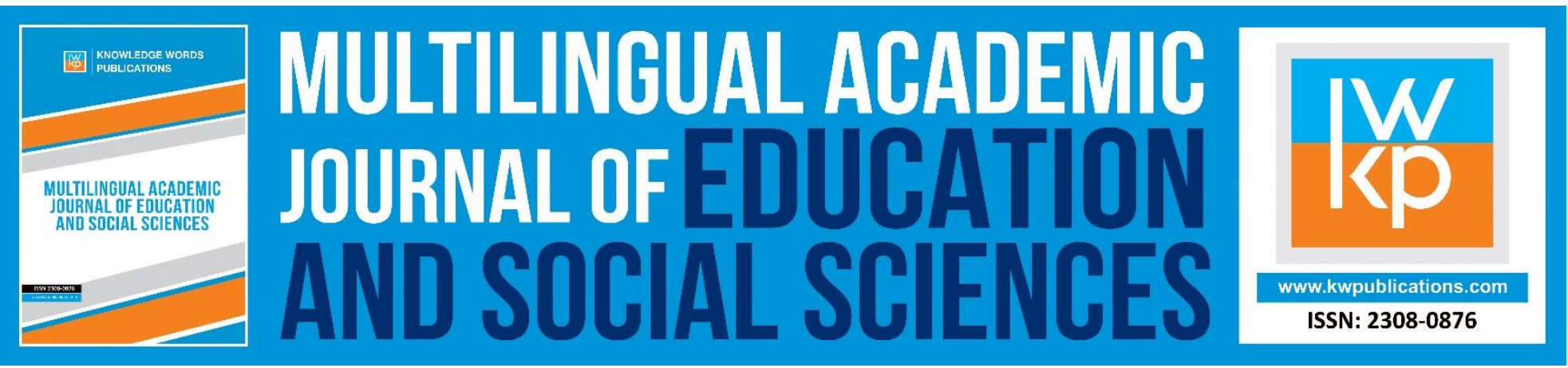

\title{
The Impact of Cultural Intelligence on Competitive Intelligence
}

\section{Ozhan Karimi \& Razieh Eshaghi}

To Link this Article: http://dx.doi.org/10.46886/MAJESS/v6-i1/4510

DOI: 10.46886/MAJESS/v6-i1/4510

Received: 01 May 2018, Revised: 15 August 2018, Accepted: 22 September 2018

Published Online: 21 October 2018

In-Text Citation: (Karimi \& Eshaghi, 2018)

To Cite this Article: Karimi, O., \& Eshaghi, R. (2018). The Impact of Cultural Intelligence on Competitive Intelligence. Multilingual Academic Journal of Education and Social Sciences, 6(1), 48-62.

\section{Copyright: (C) The Authors 2018}

Published by Knowledge Words Publications (www.kwpublications.com)

This article is published under the Creative Commons Attribution (CC BY 4.0) license. Anyone may reproduce, distribute, translate and create derivative works of this article (for both commercial and non-commercial purposes), subject to full attribution to the original publication and authors. The full terms of this license may be seen

at: http://creativecommons.org/licences/by/4.0/legalcode

\section{Vol. 6, No. 1, 2018, Pg. $48-62$}

Full Terms \& Conditions of access and use can be found at https://kwpublications.com/pages/detail/publication-ethics 


\title{
The Impact of Cultural Intelligence on Competitive Intelligence
}

\author{
Ozhan Karimi ${ }^{1} \&$ Razieh Eshaghi \\ ${ }^{1}$ Assistant Professor, Department of Management, Payame Noor University, Tehran, Iran, \\ 2 Masters student, Executive Management, Payame Noor University, Tehran, Iran. \\ Email: karimi_o@gmail.com, rahiii.eshaghi@gmail.com
}

\begin{abstract}
Competitive intelligence is goal-oriented monitoring of the competitive environment where organizations operate and compete with the aim of strategic decision making. The ability to collect, analyze and review the environmental information of competitors, customers, suppliers and trends in the competitive intelligence market is called "systematic process". Iran consists of several subcultures; therefore, attaining cultural intelligence is considered a functional skill to acquire and improve. In this regard, the question to pose is whether cultural intelligence influences competitive intelligence? This study concerns the concepts of cultural intelligence and competitive intelligence and their relationship in Iranian knowledge-based organizations. Moreover, it tries to expand the knowledge boundaries in this field. Indeed, this study is an applied research paper carried out by survey. The research data were collected through nonrandom sampling of knowledge-based companies from the research population using a questionnaire. In order to analyze the data, LisreL and SmartPls software was used in structural equation method, and to calculate the reliability of the questionnaire, Cronbach's alpha test was employed. The results show that cultural intelligence has an impact on the competitive intelligence of knowledge-based organizations in Iran, and in order to enjoy competitive intelligence, it is essential to benefit from cultural intelligence.
\end{abstract}

Keywords: Cultural Intelligence, Competitive Intelligence, Knowledge-Based Organizations.

\section{Introduction}

Knowledge-based organizations are founded with an aim of synergizing science and wealth as well as expanding knowledge-based economy with both scientific and economic objectives. By

\footnotetext{
${ }^{1}$ Assistant Professor, Department of Management, Payame Noor University, Tehran, Iran karimi_o@gmail.com

${ }^{2}$ Masters student, Executive Management, Payame Noor University, Tehran, Iran rahiii.eshaghi@gmail.com
} 
MULTILINGUAL ACADEMIC JOURNAL OF EDUCATION AND SOCIAL SCIENCES

Vol. 6 No. 1, 2018, E-ISSN: 2308-0876 @ 2018 KWP

employing knowledge capital, innovation and inventive procedures, these organizations are considered a key factor in today's science-based economy. In other words, these are the knowledge-based organizations that promote science-based economy. Science-based economy comprises production, distribution, science application and information accumulation, and has been directed specific attention.

These firms enjoy entrepreneurship procedures, such as innovative designing, distributing, providing services and devising strategies, by which tacit and novel requests by customers can be identified and handled. Among the key properties of knowledge-based organizations, desire to progress, inventive work and intelligent promotion are to mention. These organizations attempt to augment economy, enhance employment in the country and identify the best approaches to entrepreneurship. Knowledge-based organizations are corporations and law institutions generating science-based businesses with an aim of sustainable transformation of knowledge to wealth. In addition, their economic activities are in line with research and development in the field of new and advanced technologies, and helps develop the scienceeconomy in the community. The main investment in these corporations is their intelligence capital. The competitive advantage of a knowledge-based organization is obtained by knowledge and its effective use. Knowledge-based organizations need modern tools to develop strategies to be able to survive in today's competitive environment.

Among these tools are competitive intelligence which helps managers of organizations and companies to make more efficient decisions. Furthermore, the necessity of competitive intelligence in reducing risk and uncertainty in decision making is clearly evident and in order to achieve better results in business, competitive analysis of information is considered indispensable. Many societies are made up of a variety of subcultures, each of which requires recognition, pattern design, and communication framework. The vast variety of the characteristics of people, nationalities, religions, races, languages and subcultures in Iran has led to an obstacle to the collection of competitive information from the diverse regions of the country, thereby decelerating the formulation of appropriate strategies in organizations. The benefits of cultural intelligence and adaptability to different cultures provide an accurate scrutiny and interpretation of environmental information and create competitive intelligence in an environment of subcultures. The current research attempts to design a systematic and developed framework for cultural intelligence, competitive intelligence and the reliability of competitive intercultural information in knowledge-based organizations. Considering the importance of knowledge-based organizations in economic development and job creation in the country, cultural intelligence, competitive intelligence and existing subnational cultures in the country are of great importance and the necessity of this research has been formed.

\section{Cultural Intelligence}

The issue of cultural intelligence has recently been highlighted in management areas, and has been verified to improve the productivity of collections. Indeed, the ability to adapt to unfamiliar values, traditions and customs and the skill to work in a different cultural setting represent cultural intelligence. The notion of cultural intelligence was first introduced by Earley and Ang of London Business School researchers, and was published in a book titled "Cultural Intelligence, individual exchanges between cultures". Cultural intelligence has defined the aptitude to learn new patterns in cultural interactions, and provides correct behavioral responses to these 
MULTILINGUAL ACADEMIC JOURNAL OF EDUCATION AND SOCIAL SCIENCES

Vol. 6 No. 1, 2018, E-ISSN: 2308-0876 @ 2018 KWP

patterns (MacNab, 2012). In the face of new cultural situations, it is quite hard to find signs that can be used to communicate. In such cases, according to the existing information, a common cognitive framework is being developed, to communicate and acquire information (Adair Wendi et al., 2013). It can also be argued that the elaboration of such a framework is only left to those who have high cultural intelligence (Ang \& Christine, 2007). In another definition, cultural intelligence is an individual's ability to understand and act effectively in situations of cultural diversity, which helps establish effective intercultural communication (Ascalon et al., 2008). As a matter of fact, cultural intelligence reflects the individual's capability to act and manage efficiently in culturally-different situations. The composition and components of cultural intelligence are based on prediction of cultural judgments, decisions in different circumstances, cultural adaptation and promotion of work performance (Crowne, 2013).

Cultural intelligence, however, is different from social and emotional intelligence. A person with high cultural intelligence has the knack to learn in a new cultural environment and enjoys the encounter. Cultural intelligence consists of dimensions of strategy, knowledge, motivation and behavior related to different cultural situations (Blasco et al., 2012). In fact, cultural intelligence strategy includes developing a pre-cultural strategy, examining assumptions when dealing with and modifying mental maps and previous expectations. The intelligence combines the four talents of understanding, initiative, expectation, and talent to justify thought in a given direction (Pasha, 2007). A consortium of professors from the United States and England and Asia identified cultural intelligence as a systematic assessment of individual capacity for confronting individuals from different cultures (Benton \& Timothy, 2009). Cultural intelligence knowledge includes information and awareness of the norms, activities and contracts in various cultures deriving from individual and educational businesses and focuses on the special capabilities that are required for high quality and effective personal relationships in different cultural contexts. Cultural intelligence motivation reflects the ability and desire to learn and practice in different cultural situations, and to have verbal and non-verbal behaviors when communicating with people from other cultures (Gregory et al., 2009).

Cultural intelligence has three cognitive, behavioral, and motivational dimensions. The cognitive dimension is one of the rational, intellectual and mental components of cultural intelligence, and emphasizes the learning of the beliefs and customs of different cultures. The behavioral dimension of cultural intelligence is a set of individual behaviors that are necessary for effective cultural interaction. The motivational or emotional dimension of cultural intelligence highlights the importance of one's attitude or inspiration towards intercultural interactions. A person who does not believe in interactions with people from other cultures is unlikely to be disappointed with his first failure, and does not lose his motive; therefore, he adapts himself to the conditions. It will not be cultural (Raghuram, 2006). In this regard, the most important point of cultural intelligence is the concept of culture alone, its dynamic and applied aspect, and this is what many sociologists and anthropologists have emphasized (Earley, 2002). From the structural perspective, an intelligent organization focuses on the use of technology-driven and ecoarchitectural structures as well as using intelligent technology through continuous monitoring and central management (Rouach \& Santi, 2001).

Most studies on cultural intelligence are based on the division proposed by the Center for Global Cultural Intelligence. In order to measure its cultural intelligence, the Center considers it to have four dimensions of knowledge, strategy, motivation and behavior. This four-dimensional 
MULTILINGUAL ACADEMIC JOURNAL OF EDUCATION AND SOCIAL SCIENCES

Vol. 6 No. 1, 2018, E-ISSN: 2308-0876 @ 2018 KWP

approach has a great deal of overlap with other categories. Knowledge of cultural intelligence reflects an individual's perception of cultural similarities and differences, and shows the general knowledge of the person regarding other cultures. The cultural intelligence strategy reflects how one perceives intercultural experiences. This strategy represents the processes people use to understand cultural knowledge when judging their intellectual processes. Cultural intelligence motivates people's desire to experience other cultures and communicate with different people in other cultures. This includes the individuals' internal value for multicultural interactions, and the confidence that enables them to act properly in different cultural contexts (Khashi \& Harandi, 2015). Cultural intelligence behavior reflects the individual's aptitude to acclimate with verbal and non-verbal behaviors while dealing with different cultures.

\section{Competitive Intelligence}

In recent years, competitive intelligence has become one of the key concepts of management, which has been incorporated into the principles of leading companies. Competitive intelligence provides managers with the ability to innovate more creatively, use the business environment information, and employ data from competitors' analysis in organizational decision-making. Competitive intelligence is goal-oriented monitoring of the competitive environment in which organizations operate and compete with an aim of strategic decision making. In other words, competitive intelligence can be considered as the art of absorbing and transferring knowledge of meta-organizational and environmental elements in specific rules for the protection against competitive threats, as well as recognition and exploitation of potential environmental opportunities (Fleisher, 2008).

Competitive intelligence is dynamic business knowledge for collecting, analyzing and managing information coupled with understanding the concept of competition in corporate strategy for gaining competitive advantage in the business environment (Ovsanka \& Diacicova, 2008). Competitive intelligence is one of the fast-growing concepts, with the growth of the Competitive Intelligence experts by $40 \%$ per year (Fatemi \& Aligholi, 2016). In order to enhance its competitive intelligence, an organization needs goal-oriented and coordinated monitoring of its own environment and identifies a systematic framework for monitoring the environment and receiving accurate, up-to-date and tailored information (Johns \& Latitude, 2010). Basically, competitive intelligence involves market intelligence, competitor intelligence, technological intelligence and strategic intelligence. It also includes supplying customers' needs and preferences to new markets and creating opportunities and major changes in the marketing along with the distribution of market intelligence competitors. Competitor intelligence also makes systematic and continuous review of changes in the structure of rivals, products and new competitors. As far as the technological intelligence is concerned, the benefits and costs of the latest technology and the prediction of future gadgets must be considered. The study of the macro environment, tax and government regulations, social policy discussions and human resource issues will enhance the strategic social intelligence of the organization (Harandi et al., 2015).

Competitive intelligence is the ability to predict actions in a competitive environment, and to reduce uncertainty in managerial decisions. From the perspective of the French School of Management theory, competitive intelligence is categorized into four dimensions of marketing intelligence, intelligence of competitors, intelligence of technology, social strategic intelligence. 
MULTILINGUAL ACADEMIC JOURNAL OF EDUCATION AND SOCIAL SCIENCES

Vol. 6 No. 1, 2018, E-ISSN: 2308-0876 @ 2018 KWP

Commercial marketing intelligence to adapt to competitive changes in the existing market, and the changes in consumer purchasing behavior should be periodically reviewed and addressed to track trends of customers and their preferences. In new markets, innovative segmentation opportunities, marketing and distribution changes are identified through this intelligence, and then information obtained from buyers, customers, and suppliers is collected and analyzed. The competitors' intelligence to assess the competitive strategy of the organization concerns the changes in the structure of competitors, replacement for products and newcomers into the industry (Chavoshi \& Pourfar, 2012). Any information regarding the competitors' capabilities is a solid basis for improving the market position and designing strategic plans, including customer information, costs and the price of the research and development process (Maram et al., 2010). Technology intelligence addresses the cost and utilization of current and future technology which anticipates future technological changes, and deals with basic and applied research, factories, processes, norms and patents (Haghi, 2005). Strategic social intelligence encompasses intelligence and environmental information from laws and regulations, tax issues, political and economic issues, as well as social issues and human resources (Plum, 2007).

\section{Investigating the Impact of Cultural Intelligence on Competitive Intelligence through Competitive Information Validity}

The ability to collect, interpret and apply information in multi-cultural situations is very difficult, and requires the talent to understand the communication framework, norms, cultural values, and the ability to adapt and culturally interact with others. The fear of cultural differences and the emphasis on the stereotypes of others can undermine the credibility of the information obtained (Dehghanan \& Harandi, 2005).

It can be said that multiculturalism is like a double sword. On the one hand, people's worldviews are expanded, making it more intelligent to develop their own strategies through new knowledge, and on the other hand, it can be a source of pressure and conflict, which supersedes and undermines the credibility of intercultural communication and information (Livermore, 2013). Cultural intelligence is the ability to act effectively in national, ethnic and religious cultures. Intercultural high-culturally intelligent staffs have the ability to reconcile themselves and their perceptions with different subcultures; therefore, intercultural knowledge is more reliable and consistent. This will create smarter competitive strategies and could enhance the competitive intelligence of the organization. Cultural intelligence is a stick that can create diverse, coherent and harmonious environments, which brings about a competitive superiority.

\section{The Research}

\section{Conceptual Model of Research}

The conceptual framework helps to take specific relationships into account and tests those relationships to obtain scientific results from the research. A conceptual model was developed to investigate the effect that cultural intelligence can have through the credibility of information on competitive intelligence based on Fahy 2007's research on Competitive Intelligence and the Earley and ang Model 2003 in the field of Cultural Intelligence. It has three variables: independent variable (cultural intelligence), intermediary variable (credibility of competitive information), and dependent variable (competitive intelligence). 

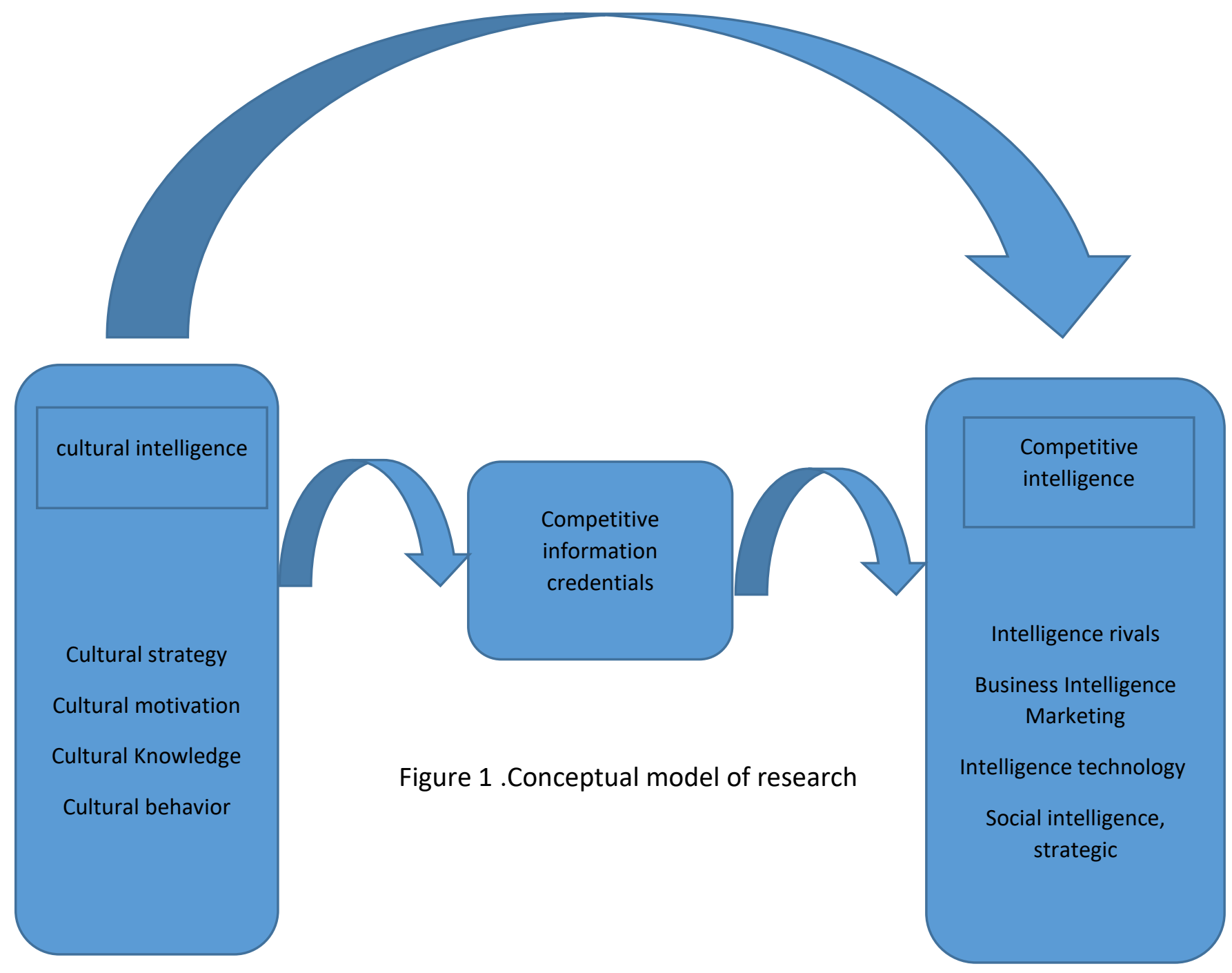

\section{Research Hypotheses}

First hypothesis: Cultural intelligence of employees is effective on the validity of competitive information.

Second hypothesis: Cultural intelligence of employees is effective on competitive intelligence. Third hypothesis: The validity of competitive information obtained on competitive intelligence is effective.

Fourth hypothesis: Cultural intelligence of employees is effective through competitive credentials on competitive intelligence.

\section{Research Methodology}

In order to explain the research method, the type of research should first be determined (Hafezienia, 2009). Research methods in behavioral science are usually classified according to 
MULTILINGUAL ACADEMIC JOURNAL OF EDUCATION AND SOCIAL SCIENCES

Vol. 6 No. 1, 2018, E-ISSN: 2308-0876 @ 2018 KWP

two criteria of purpose and nature. Obviously, statistical population is a set of individuals or objects (units) that have at least a common attribute. The current study is an applied research containing a survey. The statistical population of knowledge-based companies was from a scientific community and a non-random sampling method was used. To determine the sample size, according to the size of the statistical population, the template table was used and the sample size of 330 was obtained.

The questionnaire was based on a combination of a questionnaire used in the Cultural Intelligence departments of Research and Collaborators in 2009 and a questionnaire used in the Competitive Intelligence Unit Fahi 2007 and researcher-made items for assessing the validity of competitive information (Fahey, 2007). Moreover, it has been developed by Delphi panel method in most of the 5 Likert scale. To assess the validity of the questionnaire, two types of content validity and convergent validity were considered. The convergent validity of this principle is the one whose indices are intermediate with each other. For this purpose, the mean of output variances is greater than 0.5 and their coefficients indicate how much of the variable variance of the model is described by a separate component. By examining the results of the output of the PLS, we found out that the average variance of all variables is higher than 0.5 , so it is concluded that the components can adequately explain the variance of the variables of the research model. Therefore, it can be said that the instrument of measuring the research has a proper validity. Cronbach's alpha test was used to calculate the reliability coefficient of the questionnaire, and to ensure the internal consistency of the instrument, which indicates the reliability of the questionnaire.

Table 1. Validity and Reliability of the Questionnaire

\begin{tabular}{ccc}
\hline AVE & Cronbach's alpha & Variables \\
\hline 0.5008 & 0.8845 & Cultural Intelligence \\
0.7680 & 0.7097 & Competitive Intelligence \\
0.5660 & 0.7915 & Information credentials \\
\hline
\end{tabular}

\section{Analysis Method}

After the researcher collects extracts and classifies the data, a new phase of the research process, known as the data analysis, must begin. In the analysis stage, the important point is that the researcher should analyze information and data in the direction of the target, answering research questions, and evaluating their hypotheses. In this research, structural equation modeling and partial least squares method have been used to test hypotheses and model survival. In order to test a particular model of the relationship between variables, we use the structural equation modeling analysis, which is a special causal structure between a set of invisible structures.

Structural equation modeling is a very comprehensive and powerful technique of multiregulating regression family and more precisely the extension of a general linear model, which allows a researcher to test a set of regression equations simultaneously. This model is a comprehensive approach to test hypotheses about the relationships between the observed variables. To analyze the data, Smartpls software and partial least squares method proposed by Haldan are used (Wu, 2010). Lisrel and PLs are two main examples of the structural equations' perceptions for examining the relationships between the variables. The PIS is major and 
MULTILINGUAL ACADEMIC JOURNAL OF EDUCATION AND SOCIAL SCIENCES

Vol. 6 No. 1, 2018, E-ISSN: 2308-0876 2018 KWP

important software for route modeling that has the ability to process and analyze raw data, design and test the model in a completely graphical way. The pls is based on variance and, in comparison with similar techniques, structural equations such as Amos and Lisrel require less constraints (Liljander et al., 2009).

\section{Research Findings}

Table 2 shows the results of a demographic survey of the examined sample.

Table 2. Demographic Findings

\begin{tabular}{llll}
\hline Percent & $\mathrm{Nr}$ & \multicolumn{2}{l}{ Demographic characteristics } \\
\hline 24.65 & 82 & Female & Sex \\
75.37 & 248 & Man & \\
16.41 & 54 & $20-25$ & \\
56.53 & 186 & $25-30$ & Age \\
16.10 & 54 & $30-40$ & \\
8.2 & 27 & $40-50$ & \\
2.7 & 9 & Above 50 & \\
6.07 & 20 & Bachelor's license & \\
29.17 & 96 & Bachelor & education \\
54.104 & 179 & MA & \\
10.63 & 35 & Ph.D & Marital \\
25.23 & 84 & Single & status \\
64.13 & 211 & Married & Others \\
10.63 & 35 & &
\end{tabular}

\section{Fitness Indicators}

Various types of tests are generally termed endurance indicators and are constantly compared, evolved and developed. In this study, the general criterion (GoF) for partial least squares method is considered. Indicators of this criterion range from zero to one and are divided into four absolute, relative, internal and external models. (Zhang, 2009). Indicators are absolute and relative indicators of qualitative and descriptive. Studies demonstrate that the value of a good indicator of goodness depends on the internal model rather than on the external model. According to Table 3, the values of model indices represent the good model's validity and the research model is confirmed.

Table 3. Fitness Indicators

\begin{tabular}{cc}
\hline amount & Fitness Indicators \\
\hline 0.650 & Absolute \\
0.842 & Relative \\
0.871 & Internal model \\
0.954 & Exterior model \\
\hline
\end{tabular}


MULTILINGUAL ACADEMIC JOURNAL OF EDUCATION AND SOCIAL SCIENCES

Vol. 6 No. 1, 2018, E-ISSN: 2308-0876 @ 2018 KWP

\section{Path Analysis}

The generalization regression analysis method is a regular regression that, in addition to expressing direct effects, can show the indirect effects and the total effect of each of the independent variables for dependent variables, and interprets the relationships and correlations observed between them. In the field of social and economic studies, there are many multivariate analysis methods that examine the effects and relationships between the studied variables and mainly examine the direct effects of a variable on one another. The analysis of the pathway for the development of regression methods and the use of multiple regressions is related to the obvious formulation of causal models, which aims at obtaining quantitative estimates of the causal relationships between a set of constructs. The deductions depend on the paths that determine the study plan and flow in the path analysis of the relationships between the variables in one direction and are considered as distinct paths. 


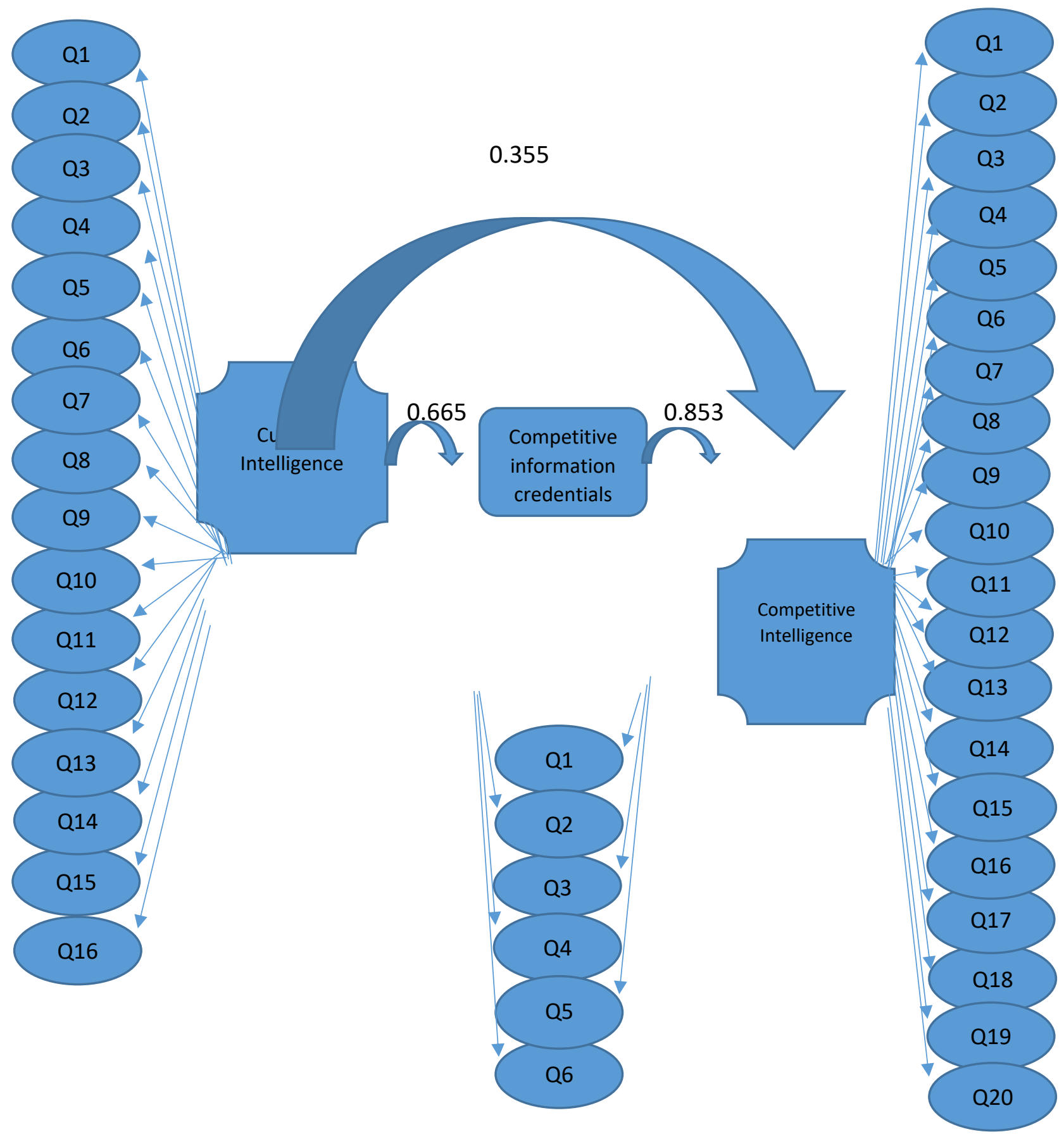

Figure 2. Path analysis

\section{Examine Assumptions}

The results of testing hypotheses in the form of path coefficients with a significant level and in relation to the research hypotheses are shown in Table 4 and 5. In Table 4, the values of the path coefficient and their significance for each of the hypotheses are examined. If the desired value is less than 0.05 , then the path and path coefficient of the view are significant and the hypothesis is confirmed, otherwise the path is not significant and the related hypothesis is rejected. 
MULTILINGUAL ACADEMIC JOURNAL OF EDUCATION AND SOCIAL SCIENCES

Vol. 6 No. 1, 2018, E-ISSN: 2308-0876 @ 2018 KWP

Table 4. Examining straight paths

\begin{tabular}{|c|c|c|c|c|}
\hline Result & $\begin{array}{l}\text { Standard } \\
\text { error level }\end{array}$ & $\begin{array}{c}\text { Test } \\
\text { statistic }\end{array}$ & $\begin{array}{c}\text { Path } \\
\text { coefficient }\end{array}$ & Direct Path \\
\hline approved & 0.000 & 8.805 & 0.665 & $\begin{array}{l}\text { Competitive information credentials } \\
\text { Cultural Intelligence }\end{array}$ \\
\hline approved & 0.000 & 6.596 & 0.355 & $\begin{array}{l}\text { Competitive intelligence } \longleftarrow \text { Cultural } \\
\text { Intelligence }\end{array}$ \\
\hline approved & 0.000 & 10.001 & 0.853 & $\begin{array}{l}\text { Competitive intelligence } \longleftarrow \text { Competitive } \\
\text { information credentials }\end{array}$ \\
\hline
\end{tabular}

In the first case, the path coefficient is 0.665 . Moreover, with a standard error rate of less than 0.05 , it can be said that with a probability of $95 \%$ of cultural intelligence, the validity of competitive information is effective and the first hypothesis is confirmed. In the second hypothesis, the path coefficients are 0.355 and 0.853 , respectively, and the standard error level is significant. Therefore, it can be stated that cultural intelligence and the validity of competitive information are effective on competitive intelligence.

In the fourth hypothesis, the effect of cultural intelligence on competitive intelligence through the validity of competitive information is considered indirectly, and the product of the direct effect of cultural intelligence on the reliability of competitive information is directly derived from the validity of competitive information on competitive intelligence.

$0.665 * 0.853=0.567$

Table 5. Reviewing the main hypothesis

\begin{tabular}{llll}
\hline Result & $\begin{array}{l}\text { Path } \\
\text { coefficient }\end{array}$ & Through & Indirect Path \\
\hline approved & 0.567 & $\begin{array}{l}\text { Competitive } \\
\text { information credentials }\end{array}$ & $\begin{array}{l}\text { Competitive intelligence } \\
\text { Intelligence }\end{array}$ \\
& & Cultural
\end{tabular}

According to the results, it can be seen that cultural intelligence is obtained through the validity of competitive information and is influenced by competitive intelligence, in which case the fourth hypothesis, which is the main hypothesis of the research, is confirmed.

\section{Conclusion}

In addition to having individual and technical skills, managers of today's organizations, should have the appropriate cultural and emotional intelligence. Nowadays, further attention is focused on cultural intelligence and the effort to access competitive intelligence. One of the main necessities of research in management science is the cultural context. A competitive tool in today's societies, specifically for the emerging and knowledge-based companies, is competitive intelligence. One of the main tasks of knowledge-based organizations is the management of mental and intellectual capital of the organization. In order to gain competitive intelligence, an organization must always seek and win competitive information from the market, customers, competitors and industry so that the credibility of the obtained information is of a higher value, 
MULTILINGUAL ACADEMIC JOURNAL OF EDUCATION AND SOCIAL SCIENCES

Vol. 6 No. 1, 2018, E-ISSN: 2308-0876 @ 2018 KWP

and will lead to the development of competitive intelligence and compilation of more competitive strategies.

Iran is a country that consists of several subcultures with language, religion, different principles and norms (Moon, 2010). Therefore, it is difficult to obtain competitive information in an environment with different cultures, and its interpretation and analysis require special skills. In order to understand this concept further and to carry out research in this field, any researcher needs to know certain components (D'andrade, 2000).

The current study is a developed model designed to examine the effect of competitive intelligence on cultural intelligence. The empirical findings are widely supported by the theoretical model of the present research, and in the light of the results, cultural intelligence is influenced and validated by the validity of competitive information on competitive intelligence. Cultural intelligence is the ability to recognize cultural differences, and organizations with a high cultural intelligence have the ability to establish effective relationships with different subcultures, which helps them capture their competitive information from different cultures, and analyze the Information efficiently.

The findings of this study are consistent with the Aspinall studies of 2011, and Ascalon et al., 2008. Highly Intercultural-intelligent staff has the ability to reconcile themselves and their perceptions with different subcultures, which makes intercultural knowledge more reliable and consistent. This will create smarter competitive strategies, and enhances the competitive intelligence of the organization. Cultural intelligence is a systematic assessment of the individual's capacity to deal with people from different cultures. Paying attention to multiple subcultures helps managers and staff of the Iranian knowledge-based organizations to pay attention to the high cultural credibility of all the cultures of the country to improve the organization's cultural intelligence. By studying the cultural characteristics of different Iranian nations and nationalities, Firms can increase their knowledge and, given the impact of cultural intelligence on competitive intelligence, can collect and interpret competitive information, and develop intelligent strategies in their competitive environment.

\section{References}

Ang, S., Van D., \& Christine, K. (2007). Cultural Intelligence: it's Measurement and Effects is Cultural Judgment and Decision Making, Cultural Adaptation and Task Performance, 5(8),10-22.

Aspinall, Y. (2011). Competitive intelligence in the biofarmaceutical industry: The key elements. Business Information Review, 28(2), 101-104.

Benton, G., \& Timothy, H. (2009). Globalization Cultural Intelligence and Maritime Education. USA: California State University.

Blasco, M., Liv F. E., \& Jakobsen, M. (2012). If only cultural chameleons could fly too: A critical discussion of the concept of cultural intelligence. International Journal of Cross Cultural Management, 12(2), 229-245.

Chavoshi, K., \& Pourfar, J. M. (2012). Investigating the Effect of Competitive Productivity in Companies. Accepted in the Tehran Stock Exchange and the Impact of the Type of Industry on the Second Executive Management Conference, July.

Crowne, K. (2013). Cultural exposure, emotional intelligence, and cultural intelligence: An exploratory study. International Journal of Cross Cultural Management, 13(1), 5-22. 
MULTILINGUAL ACADEMIC JOURNAL OF EDUCATION AND SOCIAL SCIENCES

Vol. 6 No. 1, 2018, E-ISSN: 2308-0876 @ 2018 KWP

D'andrade, R. (2000). The development of cognitive anthropology. Cambridge: Cambridge University Press.

Dehghanan, H., \& Harandi, A. (2015). The Study of the Impact of Social Capital on Innovative Performance, Emphasizing the Meaning of Transfer of Knowledge. Journal of Innovation Management, 9(1), 32-45.

Earley, P. C. (2002). Redefining interactions across cultures and organizations: moving forward with cultural intelligence. Research in Organizational Behavior, 24(2), 271-299.

Fahey, L. (2007). Connecting strategy and competitive intelligence: Refocusing intelligence to produce critical. Strategy inputs, Strategy Leadership, 35(1), 4-12.

Fatemi, S., \& Aligholi, M. (2016). Assessing the relative importance of later understanding of the competitive environment of competitive competitors for marketing strategies. second international management conference in Tehran, 21, Tehran, in September.

Fleisher, C. S. (2008). Using open source data in developing competitive and marketing intelligence. European Journal of Marketing, 42 (7), 852-866.

Gregory, R., Priying, M., \& Beck, R. (2009). The role of cultural intelligence for the emergence of negotiated culture in IT offshore outsourcing projects. Information Technology \& People, 22(3), 223-241.

Hafezienia, M. (2009). Introduction to the Research Method in Humanities. Cheshmeh: Tehran. Haghi, N. J. (2005). Competitive intelligence, Tadbir magazine, 154-187.

Harandi, A., Yar, S. F., \& Fatemi, Z. (2015). Modeling the Effect of Organizational Image on Consumers in Service. New Marketing Research Quarterly, 13(4), 56-71.

Johns, P., Latitude, C. (2010). Competitive intelligence in service marketing A new approach with practical application. Marketing Intelligence \& Planning, 28(5), 551-570.

Khashi, V., \& Harandi, A. (2015). the role of cultural intelligence in promoting competitive intelligence. Quarterly Journal of Human Resources Management Research, 21(5), 33-51.

Liljander, V., Polsa, P., Riel, V. A. (2009). Modeling consumer responses to an apparel store brand: Store image as a risk reducer. Journal of Retail and Consumer Services, 16(3), 281-290.

Livermore, D. (2013). Clever Cultural Leadership a new success code. Islamic Azad University: Isfahan.

Ma, A. E., Deidra, S. J., \& Marise, B. Ph. (2008). Cross-cultural social intelligence Cross Cultural Management, 15(2), 109-130.

MacNab, B. (2012). An experiential approach to cultural intelligence education. Journal of Management Education, 36(1), 66-94.

Maram, P. A., Eskandari, K., \& Molavi, Z. (2010). Competitive Intelligence, Tracking of Competitor Movements. Tedbir Magazine, 214-223.

Moon, T. (2010). Organizational cultural intelligence: Dynamic capability perspective. Group \& Organization Management, 35(4), 456-493.

Ovsanka, P., \& Diacicova, A. (2008). Competitive Intelligence in Chemosvit a.s. Conference on Professional Information Resources for Business, Marketing, Competitive Intelligence and Knowledge. Management Prague 6, Diplomat Hotel, 5-6. February.

Pasha, S. (2007). Theory and Application of Intelligence and Personality Examinations. Tehran: Iran.

Plum, E. (2007). Cultural intelligence: The art of leading cultural complexity. UK: Middlesex University Press. 
Raghuram, S. (2006). Individual effectiveness in outsourcing. Human Resource Management, 25 (2), 127-133.

Rouach, D., \& Santi, P. (2001). Competitive intelligence adds value. European management journal. 19 (5), 200-224.

Wendi, A. L., Hideg I., \& Jeffrey, S. R. (2013). The culturally intelligent team: the impact of team culture intelligence and cultural heterogeneity on team. shared values. Journal of CrossCultural Psychology, 44(6), 941-962.

Wu, W. S. (2010). Linking Bayesian networks and PLS path modeling for causal analysis. Expert Systems with Applications, 37(4), 134-139.

Zhang, Y. (2009). A Study of Corporate Reputation's Impact on Customer Loyalty Based on the PLS-SEM Model. International Business Research, 2(3), 28-35. 